\title{
Das modas às tintas: representações do feminino nas publicidades da revista Anuário das Senhoras (1940-1950)
}

From fashion to paints: representations of the feminine in the advertisements of the magazine Anuário das Senhoras (1940-1950) 


\section{Ramona Lindsey Rodrigues Mendonça ${ }^{1}$}

ORCID: https://orcid.org/0000-0003-3942-6132

\section{Francisco Fabiano de Freitas Mendes ${ }^{2}$}

ORCID: https://orcid.org/0000-0003-1232-9391

[resumo] Análise sobre representações do feminino a partir dos anúncios publicitários da revista Anuário das Senhoras (1934 a 1958). 0 recorte temporal deste artigo compreende os anúncios a partir dos anos de 1940. 0 texto é guiado pelos conceitos de moda e publicidade, e dialoga com as discussões com os autores: Svendsen, Habermas, Lipovetsky and Wicliams. Entendendo-se moda como conceito que abrange múltiplos significados, a análise dos anúncios no periódico procurou discutir sua contribuição na construção e manutenção dos papéis sociais pensados para a mulher na realidade urbana brasileira da época. Verificou-se o esforço da publicidade em equilibrar tradição e modernidade, num movimento que abria para as mulheres as portas do consumo e do trabalho ao mesmo tempo em que reafirmava seu papel central no ambiente doméstico.

\section{[palavras-chave] Imprensa. Publicidade. Moda. Mulheres.}

[abstract] An analysis of the representation of the female figure in advertisements of the magazine Anuário das Senhoras (1934-1958) This article's time frame covers advertisements starting from the 1940s. The text - guided by the concepts of fashion and advertising - dialogues with discussions developed by Svendsen, Habermas, Lipovetsky, and Wicliams. Understanding fashion as a concept that encompasses multiple meanings, the analysis of the ads in the magazine sought to discuss their contribution to the construction and maintenance of social roles thought for women in the Brazilian urban reality at the time. There was an effort by advertising to balance tradition and modernity, in a movement that opened the doors of consumption and work for women while reaffirming its central role in the domestic environment.

[keywords] Press. Publicity. Fashion. Women.

Recebido em: 28-01-2019

Aprovado em: 04-07-2019

\footnotetext{
${ }^{1}$ Mestra pelo Programa de Pós-Graduação em Ciências Sociais e Humanas da Universidade do Estado do Rio Grande do Norte e bolsista do Programa de Demanda Social da CAPES. Desenvolve atividades de pesquisa na área de História Cultural com ênfase em temáticas de moda, beleza e feiura nos periódicos e Gênero. Graduada em História pela Universidade do Estado do Rio Grande do Norte (2018). E-mail: ramonallindsey@ahotmail.com. Lattes: http://Lattes.cnpq.br/8838545661959720.

2 Professor Doutor do Departamento de História da Universidade do Estado do Rio Grande do Norte (UERN) desde 2006 e membro permanente do corpo docente do curso de Pós-Graduação em Ciências Sociais e Humanas (PPGCISH/UERN), nível mestrado, desde 2016. E-mail: fabianomendes@uern.br. Lattes: http://lattes.cnpq. br/7845344312617032.
} 
Quando se pensa na palavra moda, geralmente, alude-se ao vestuário, sua forma mais comum de apresentação e aplicação. No entanto, moda é um conceito mais amplo, como assevera Daniela Calanca (2011), podendo incluir em sua acepção, por exemplo, predileções de indivíduos, comportamentos, modos de pensar e sentir de setores sociais:

Desde que se tornou possível reconhecer a ordem típica da moda como sistema, com as suas metamorfoses e inflexões, a moda conquistou todas as esferas da vida social, influenciando comportamentos, gostos, ideias, artes, móveis, roupas, objetos e linguagem. Em outras palavras, desde que ela surgiu no Ocidente, no final da Idade Média, não tem um conteúdo específico. (CALANCA, 2011, p. 13)

A moda é capaz de permear toda a vida social, estando em variadas dimensões, não contendo ou pertencendo a um conteúdo exclusivo. Mas o que a constitui, afinal? De acordo com Gilles Lipovetsky (2009), a moda é caracterizada pelo surgimento do novo em oposição à tradição das sociedades "primitivas". Desse modo, no processo constante de novidades, a mudança torna-se um caráter fundamental da moda e responsável por trazer novos traços de modo contínuo. Essa dinâmica só é possível a partir da ruptura com as tradições, o que mais recentemente levou ao direcionamento da modernidade, já que "há na moda um traço vital da modernidade: a abolição de tradições" (SVENDSEN, 2010, p. 25), ou mesmo a sua substituição constantemente revisada com elementos novos.

Em específico a partir do século XX, a moda também atingiu o setor econômico, em especial a indústria, quando se passou a valorizar cada vez mais a aparência dos objetos, como mostra Lipovetsky:

O imperativo industrial do Novo se encarna agora numa política de produtos coerente e sistemática, a da diversificação e da desmassificação da produção. 0 processo de moda despadroniza os produtos, multiplica as escolhas e opções, manifesta-se em políticas de linhas que consistem em propor um amplo leque de modelos e versões construídos a partir de elementos-padrão e que só se distinguem ao termo da linha de montagem por pequenas diferenças combinatórias. (LIPOVETSKY, 2009, p. 187)

Dessa forma, a capacidade de mudanças na moda se evidenciou em toda forma de produção, trazendo maior variedade e considerando os valores estéticos para a venda dos produtos, já que as alterações na aparência dos itens funcionariam na sedução dos consumidores. Consequentemente, na apresentação dos objetos, a publicidade surge como a melhor arma do negócio, tornando-se encarregada de expor a cada público-alvo toda gama de mercadorias do que se tem ou se quer por novo e das mudanças; e porque não dizer do "espírito" da moda. Lipovetsky enfatiza a questão quando afirma que "no coração da publicidade trabalham os próprios princípios da moda: a originalidade a qualquer preço, a mudança permanente, o efêmero" (LIPOVETSKY, 2009, p. 215). Percebe-se, então, que moda e publicidade andariam juntas a fim de cumprir seus respectivos objetivos, que mais se cruzam do que se observam. 
A palavra publicidade possui derivação do termo latim publicus, que deu origem à palavra francesa publicité. Seu sentido etimológico revela a profunda relação do ato do "ser e tornar público".

De acordo com Jürgen Habermas, essa ligação ocorreria de forma diferenciada, com a publicidade duplamente envolvida não só com a esfera pública, mas também com a privada:

As mídias se apresentam como instâncias em que é possível voltar-se para necessidades e dificuldades pessoais, como autoridades para ajudar a viver: oferecem abundantes oportunidades para identificação, para uma espécie de regeneração do setor privado a partir dos fundos disponíveis de serviços públicos de apoio e de aconselhamento. A relação originária da esfera íntima para com a esfera pública literária se inverte: a interioridade correlata à publicidade dá tendencialmente lugar a uma retificação correlata a intimidade. A problemática da existência privada é absorvida até certo ponto pela esfera pública e, sob a supervisão de instâncias publicitárias, se não é revolvida, ao menos é difundida. Por outro lado, a consciência da privacidade se eleva exatamente através de uma tal publicidade, com a qual a esfera efetivada pelos meios de comunicação de massa assumiu traços de uma intimidade de segundo grau. (HABERMAS, 2003, p. 204)

Percebe-se que as instâncias da esfera privada passam a invadir a esfera pública, modificando sua estrutura. Essa transformação se daria principalmente pelo alto consumo das comunicações de massa, quando o jornalismo literário dá lugar à ascensão dos novos meios de mídia, nos quais a publicidade se insere e promove certo grau de intimidade ao informar seu receptor.

Partindo de uma visão mais específica da propaganda em relação ao produto, John Berger salienta que a publicidade tem a capacidade de fazer com que:

El espectador se sienta marginalmente insatisfecho con su modo de vida presente. No con el modo de vida de la sociedad, sino con el suyo dentro de esa sociedad. La publicidad le sugiere que, si compra lo que se ie ofrece, su vida mejorará. (BERGER, 2004, p. 79)

Nesse sentido, a publicidade seria capaz de provocar um desejo por aquilo que ela apresenta, criando um sentimento de necessidade ao se visualizar o produto. Ainda é nessa direção que John Berger se refere quando fala que:

La publicidad nunca es el elogio de un placer en sí mismo. La publicidad se centra siempre en el futuro comprador. Le ofrece una imagen de sí mismo que resulta fascinante gracias al producto o a la oportunidad que se está intentando vender. Y entonces, esta imagen hace que él envidie lo que podría llegar a ser. (BERGER, 2004, p. 73) 
Compreende-se, então, que ao tentar cumprir o objetivo de atingir o seu comprador, a publicidade cria uma imagem dele, construindo uma representação futura do que ele virá a ser ao usar o produto que está à venda.

De acordo com Roger Chartier (1988), as representações possuem dois aspectos que se dividem sob a forma do "modo de ver" de algo ausente e sob a forma de uma "apresentação pública de algo ou alguém" (CHARTIER, 1988, p. 20). No primeiro aspecto, as representações ocorrem de maneira "terceirizada", de modo que se dá a ler algo ausente por meio da construção material ou simbólica; no segundo, elas mostram-se intrínsecas ao ser presente, quando o próprio elemento exibe os signos interiorizados, consolidando a apropriação que pode ocorrer de forma passiva ou por meio do conflito de interesses. Além disso, o autor também frisa a relação distinta entre representação e representado, caracterizando-os como "signo e significado", respectivamente, na qual se daria a substituição da identidade do indivíduo pela aparência da representação não existindo fora de seu signo (CHARTIER, 1988, p. 21).

Roger Chartier (1988) formula sua análise acerca do "mundo como representação" por meio do exemplo da feitura de um livro, levando em consideração tanto o contexto da produção, com as intenções do autor e as relações de poder que envolvem a obra, quanto a receptividade do conteúdo por ele produzido. Utilizando a abordagem do autor como exemplo, pode-se investigar de forma análoga a revista Anuário das Senhoras e a publicidade nela veiculada. Ambas podem ser tomadas como objetos que carregaram as intenções de seus autores e permearam as relações de poder, e que puderam ser acolhidos e interpretados por quem teve acesso às publicações.

Há ainda o que Chartier chama de "efeito de sentidos das formas materiais" (CHARTIER, 1991, p. 179-180), ou seja, o Anuário das Senhoras tem formato e disposição interna característicos de um produto cultural menos voltado para o informativo do que para a consulta e a visitação constantes. Nele, as publicidades têm direção específica diante de outros anúncios em veículos de rápido consumo e circulação. Assim, esse dispositivo material e formal atinge o leitor parecendo uma maneira particular de apropriação.

Os anúncios publicitários devem ser vistos como prática cultural, ou seja, que se constituem e fazem parte de uma representação no que condiz ao sentido dos "modos de ver" que dão a ler um ausente e se apresenta por meio de suas legendas e imagens. Isso torna o anúncio publicitário um signo e, por efeito, elemento que age na realidade.

No jogo entre a representação e o ser que está representado nos anúncios e no anuário que os veiculam, alguns aspectos de realidade podem ser críveis para algumas, mas não para todas as leitoras. Assim, entende-se que as múltiplas realidades femininas não estariam abarcadas em sua totalidade e as que são criadas não se aproximariam plenamente do que realmente apresentam. Entretanto, todas estariam passíveis de uma apropriação, pois, ao entrar em contato com a revista e sua publicidade, cada leitora seria capaz de interpretar e incorporar seus signos (mesmo que de modo inconsciente) e fazer, por consequência, novas representações pela construção de uma leitura da realidade, misto de influenciada e original, na qual se inter-relacionam o prestígio do periódico, a eficiência do anúncio e a experiência pessoal. 


\section{O Anuário das Senhoras}

Constituindo-se como produção cultural impressa, o Anuário das Senhoras propicia uma visão de e para o mundo e a sociedade brasileira ao mesmo tempo que permite a leitura de seus realizadores. Mas, afinal, quem o produziu? 0 que era de fato a revista Anuário das Senhoras e quais os objetivos que estavam nesse corpo redigido? Nada melhor para começar a responder esses questionamentos do que a autorrepresentação da revista:

\footnotetext{
Está em circulação mais número do riquíssimo "ANNUARIO DAS SENHORAS", a modelar publicação que, cada anno, apparece para deleite das senhoras e senhorinhas. Editado pela Empresa de "O Malho" e organizado, como os anteriores, por "Sorcière" - a escriptora Alba de Mello - este anno o magnifico annuario prima pelo bom gosto, pela confecção que revela, pela feitura material, insuperavel, e ainda pela variedade de texto e beleza das illustrações. (PREFÁCIO..., 1940, p. 1)
}

À primeira vista, chama a atenção a altivez com que a revista se autodescreve. As designações de ser um material "magnífico" e "insuperável" são bons exemplos disso. Ainda com base nas definições elaboradas por Chartier acerca do conceito de representação, percebe-se uma forma de apresentação do objeto material da revista, isto é, ao se autodefinir, a publicação dá a ler a sua presença física, abordando sua função e seu conteúdo nela presentes. A isso pode-se atribuir a disputa de poder em que as representações se inserem, visto que, no contexto da revista, não havia somente o anuário como revista feminina. Por isso, a necessidade de autoafirmação e de se apresentar por meio de sentidos que a diferenciasse das demais: uma revista voltada para o público feminino, de periodicidade anual e em formato de brochura. Circulando entre 1934 a 1958, o Anuário das Senhoras foi dirigido por Alba de Mello e publicado pelo grupo editorial $O$ Malho, na cidade do Rio de Janeiro, editora bastante conhecida pelas revistas ilustradas de cunho humorístico e político, e que marcou uma nova fase para os periódicos no Brasil, como mostra Maria Celeste Mira:

Progresso técnico e divisão do trabalho farão das revistas do novo século um
espetáculo à altura, com muitas fotografias e ilustrações coloridas dispostas
numa diagramação mais leve e atraente. [...] Mas a grande novidade mesmo são
as mais populares e de vida mais duradoura, como a Revista da Semana, O Malho,
Fon-Fon, Careta e Dom Quixote. Nelas, acontecerá a época áurea da caricatura,
com nomes como os J. Carlos, Raul Pederneiras, K. Listo, Julião Machado e tantos
outros não menos importantes. Concentrando a carga crítica e humorística das
revistas, elas retrataram os fatos e personagens que fizeram a política, a cultura
e a vida mundana da época. (MIRA, 2003, p. 21)

Apesar de alcançar certa popularidade com seu caráter humorístico, O Malho, uma das primeiras publicações a fazer parte da empresa editorial, em 1902, ainda possuía um público muito restrito ao elitismo da classe média. Decerto, "dependendo do conteúdo, a revista era considerada uma leitura apropriada para as mulheres" (MIRA, 2003, p. 18), revistas com 
assuntos políticos como 0 Malho, entre outras produzidas pela mesma editora, certamente não seriam adequadas às moças e senhoras de uma sociedade ainda tão patriarcal. Dessa forma, para elas, as revistas como Cinearte (1926-1942), Moda e Bordado, Arte de Bordar e o Anuário das Senhoras (1934-1958), que abrangeria todos esses assuntos ligados à feminilidade, foram criadas pelo grupo editorial para esse mercado em expansão.

O conteúdo dessas publicações eram temas relacionados aos ideais de feminilidade, voltado para o espaço privado do lar, circundado principalmente pela literatura, bem como por horóscopo e assuntos acerca da moda (GARCIA, 2004, p. 34). Com a entrada das jovens brasileiras nas escolas, percebeu-se uma grande variação e amplificação dos assuntos das revistas, sendo possível notar "a diferença entre o material destinado às moças solteiras ou donzelas e às senhoras ou mães de família" (MIRA, 2003, p. 19). Desse modo, era "permitido às solteiras um pouco mais de frivolidade que a revista, pedagogicamente, pretende atenuar com a difusão de conhecimento mais útil e elevado do que a moda ou as novelas" (MIRA, 2003, p. 19). Entretanto, algumas temáticas permaneceram ligadas ao público leitor feminino, não sendo raro vê-las nas colunas e nas páginas de alguns periódicos. Isso se dá pela constituição de um campo distinto, que são as publicações da imprensa feminina, como mostra Tania de Luca:

\begin{abstract}
A imprensa feminina orbita em torno de temas mais perenes, não submetidos à premência do tempo curto do acontecimento. Moda, beleza, casa, culinária ou cuidado com os filhos comportam uma abordagem circular, ligada à natureza e às estações do ano: afinal, receitas, recomendações e conselhos indicados para o inverno ou verão podem ser retomados em anos subsequentes, desde que revestidos de ar de atualidade e apresentados como a última palavra no assunto. (LUCA, 2013, p. 448)
\end{abstract}

Os temas possuem um caráter contínuo e que podem ser sempre resgatados a partir das novidades de cada período. É nesse sentido que a revista Anuário das Senhoras trouxe em seu bojo assuntos bastante arraigados na imprensa feminina do período, com o objetivo de entreter e servir como manual de instruções às suas leitoras. De acordo com a revista:

Conhecem todas as donas de casa a utilidade dessa publicação, e é isso que [explica] a ansiedade com que o "ANNUARIO DAS SENHORAS" é esperado, nas proximidades dos fins de anno. Aliás, essa ansiedade se justifica, pois o "ANNUARIO DAS SENHORAS" não é, em absoluto, um repositório de leitura passageira, ao contrário, constitue uma espécie de "vade-mecum" feminino, util, agradavel, elegante, interessante e vantajoso, quer para senhoras, quer para senhorinhas. (PREFÁCIO..., 1940, p. 1)

As temáticas voltadas ao universo da moda, da beleza, dos cuidados do lar e da família, da saúde feminina, da culinária e da costura aparecem, pela definição do anuário, como algo necessário às mulheres, frisando sobretudo o caráter útil de suas publicações, nas quais as instruções lhes serviriam para a aplicação na vida prática. Esse aspecto se dá principalmente porque a revista tinha uma periodicidade anual e, por isso, expunha temas que não envelheciam, como, por exemplo, literatura, culinária e moda.

Além dos assuntos característicos desse tipo de impresso, a publicidade passou a fazer parte do corpo das revistas, formando a tradição perene dos anúncios em periódicos que combinava a representação e a prática conduzidas pela ideia da novidade/necessidade: 


\begin{abstract}
A publicidade também se articulou às novas demandas da vida urbana do início do século XX e, no que diz respeito à imprensa periódica, transformou-se na sua principal fonte de recursos. 0 anúncio trilhou, então, novos caminhos em relação à estrutura e linguagem e, ainda, no que concerne à profissionalização da atividade, com o agenciador individual cedendo lugar, no decorrer da década de 1910, as empresas especializadas. A voracidade dos cartazes e reclames parecia insaciável, e eles se faziam presentes nos mais diferentes espaços: muros, bondes, casas de espetáculos, restaurantes, almanaques, jornais e revistas. [...] A ilustração, com ou sem fins comerciais, tornou-se parte indissociável dos jornais e revistas. (LUCA, 2005, p. 123)
\end{abstract}

Assumindo a forma textual ou ilustrativa, as publicidades em revista passaram a se estabelecer como fonte de recursos que contribuíam nos custos e na qualidade dos impressos. Além disso, a presença delas nos periódicos também acabou por figurar um novo estilo de vida a partir de itens da modernização, na qual "velocidade, mobilidade, eficiência e pressa tornaram-se marcas distintivas do modo de vida urbano e a imprensa [...] tomou parte ativa nesse processo de aceleração" (LUCA, 2005, p. 137).

Essa realidade, tanto como presença custeadora quanto como venda da "modernidade", estava da mesma forma presente no Anuário das Senhoras. As publicidades equivaliam a boa parte da revista, ora aparecendo ao lado dos seus conteúdos escritos, ora em páginas separadas e exclusivas, seguindo a lógica do mercado publicitário.

Dessa forma, "o conteúdo do Anuário das Senhoras incluía temas veiculados em textos, imagens e publicidade, que eram dispostos de forma a contemplar tudo o que pudesse interessar às leitoras" (GARCIA, 2004, p. 42), constituindo as relações para qual a publicidade se dirige, isto é, o público e o consumo (WILLIAMS, 2011, p. 254-255). Nessa perspectiva, pode-se entender que a organização dos anúncios publicitários no Anuário das Senhoras, em sua formação intrínseca, voltava-se para o público feminino da revista com certo poder aquisitivo para a compra e para aquelas que almejavam satisfazer suas necessidades por meio da fantasia do consumo, promovendo a transformação de si mesmas e do seu contexto em função do desejo, como mostra Raymond Williams:

A publicidade, em suas formas modernas, opera para preservar o ideal de consumo das críticas inexoravelmente feita pela experiência. Se o consumo de bens individuais deixa toda essa área da necessidade humana não satisfeita, um esforço é realizado, pela mágica, para associar esse consumo com os desejos humanos aos quais ele não tem referência real. Não compramos apenas um objeto: compramos respeito social, descriminação, saúde, beleza, sucesso e poder para controlar nosso ambiente. A mágica obscurece as fontes reais de satisfação geral porque sua descoberta envolveria uma mudança radical em todo o modo habitual de vida. (WILLIAMS, 2011, p. 257)

A partir disso, compreende-se que os indivíduos em constante contato com a publicidade, cuja função, de acordo com o autor, é a de fabricar a fascinação, tendem a se transformar guiados pelo que ela anuncia. Além disso, na busca por 
anunciar os 'temas de interesse feminino', o corpo editorial do Anuário veiculava, em efeito, uma ideia, uma imagem do que seriam esses temas, ao mesmo tempo em que veiculava representações do que é ser mulher e pelo que elas se interessavam. (GARCIA, 2004, p. 45)

Isso permite refletir sobre qual tipo de transformação essa aliança de funções publicitárias e objetivos do Anuário das Senhoras levou para o público que o consumia. 0 delicado, nessa missão do periódico, era aliar os conceitos de tradição e modernidade em um balanço entre a manutenção de certas práticas do lugar social da mulher e a aquisição de elementos do universo das novidades.

\section{A mulher na estampa da publicidade}

FIGURA 1 - ANÚNCIO DO LEITE CONDENSADO NESTLÉ

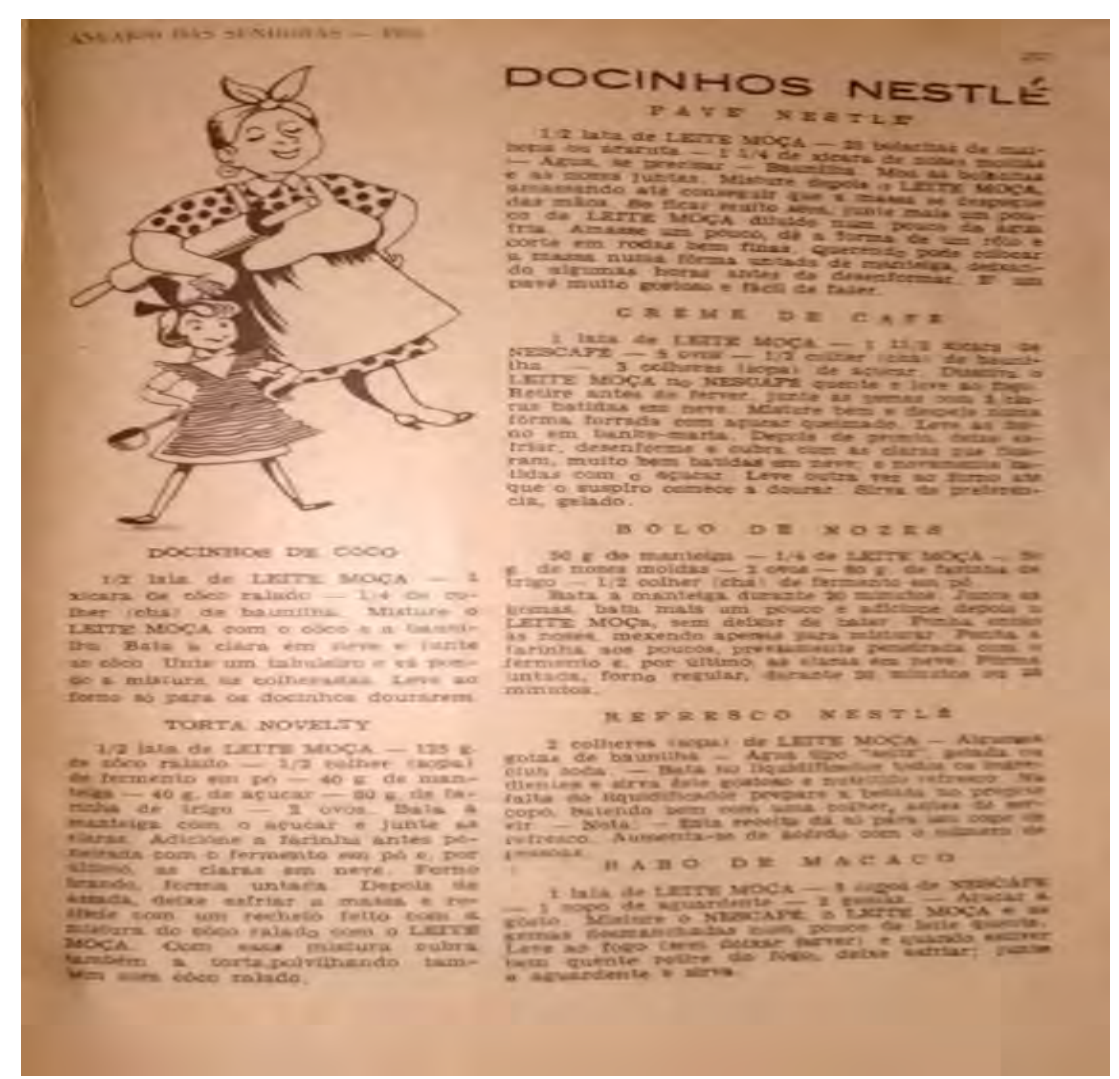

FONTE: DOCINHOS Nestlé (Nestlé). Anuário das Senhoras, Rio de Janeiro, Sociedade anônima "O malho", ano 22, p. 257, 1955. Anual.

De avental, com um rolo de massa na mão e lenço na cabeça. É como a mulher é desenhada na publicidade dos "Docinhos Nestlé". Uma menina, que aparenta ser sua filha, também figura segurando uma espécie de concha ou panela pequena e acompanha a mãe em 
um gesto de orgulho por algo feito ou por fazer. 0 arranjo da ilustração sugere que ambas estariam prontas para preparar cada sobremesa indicada, do "pavê Nestlé" aos "docinhos de coco".

Ao abordar o retrato da figura feminina em um contexto de receitas culinárias, a publicidade acaba por propor e reforçar um dos espaços que estaria destinado às mulheres na década de 1950, como mostra Denise Bernuzzi de Sant’Anna:

Entre 1930 e 1950, 'manter a linha' era um conselho comum publicado nas revistas femininas. Ainda não se falava em 'boa forma'. Os exercícios aconselhados destinavam-se, em geral, a afinar a cintura e a endireitar a postura. [...] As seduções se limitavam por medo de virar 'moça perdida'. A beleza rimava com uma certa contração da postura e alguma dose de cerimônia nos gestos. A demonstração de pudores hoje esquecidos não era incomum. [...] Precisavam ser cândidas e obedientes diante do ideal da esposa fiel. Como um anjo da família, dela se esperava uma força inabalável, emoldurada por uma graça irresistível. Robustez do espírito e graça corporal. (SANT’ANNA, 2013, p. 110)

Em uma acepção ampla, a moda feminina para a época, ou seja, os traços idealizados pela sociedade, ainda seria a daquela responsável por cuidar do lar, da família e dos filhos, e, trazendo para essa publicidade em específico, cuidar expressava o ato de alimentar os familiares. Percebe-se certo sentido na própria marca do produto, que tanto abrange a ideia por meio do seu nome "Nestlé", que significa "pequeno ninho" em alemão, quanto do seu logotipo, que traz um pássaro fêmea alimentando seus filhotes. Desse modo, a perspectiva de um produto voltado para a alimentação e para a família - tendo a figura da mulher como mediadora e encarregada da função de escolher o melhor para sua prole - reforça uma tradição arraigada em uma estrutura social conservadora brasileira. A expressão de orgulho estampada no rosto e na postura da mãe poderia simbolizar essa noção: ao contemplar essas receitas estaria consciente de que ofereceria o melhor para seu lar.

Pode-se ler também o semblante de felicidade da mãe associado à imagem da filha, que, por estar perto de si e dos utensílios que sinalizam o ato de cozinhar, estaria aprendendo o manejo da comida e deixando sua mãe orgulhosa. 0 papel da mulher nessa representação não seria somente o de nutrir a família, mas também o de ensinar e transmitir as "boas maneiras" para sua filha por meio do fazer as receitas. Verificam-se esses aspectos não só nessa publicidade, mas em vários outros anúncios presentes no anuário, como o do suco de tomate da marca Peixe, produzido pelas Indústrias Alimentícias Carlos de Brito S.A., que traz em sua chamada:

É um prazer servir. Bebida deliciosa, feita com os sumarentos tomates "Beauty", altamente selecionados. Alimento nutritivo de grande valor contendo as vitaminas A, B, C e G. Já vem pronto para servir. - Também pode ser servido quente como sopa, bastando adicionar pequena quantidade de caldo fervendo e manteiga. (É UM PRAZER..., 1955, p. 138) 
A publicidade, por meio da frase "é um prazer servir", faz uso da ambiguidade para se referir tanto à bebida que já vem preparada, quanto à imagem (figura 2) que é exposta: a mulher surge segurando uma jarra prestes a despejar seu conteúdo em um copo, e o marido e o filho contentes pela ação da mãe e esposa.

\section{FIGURA 2 - ANÚNCIO DO SUCO DE TOMATE PEIXE}

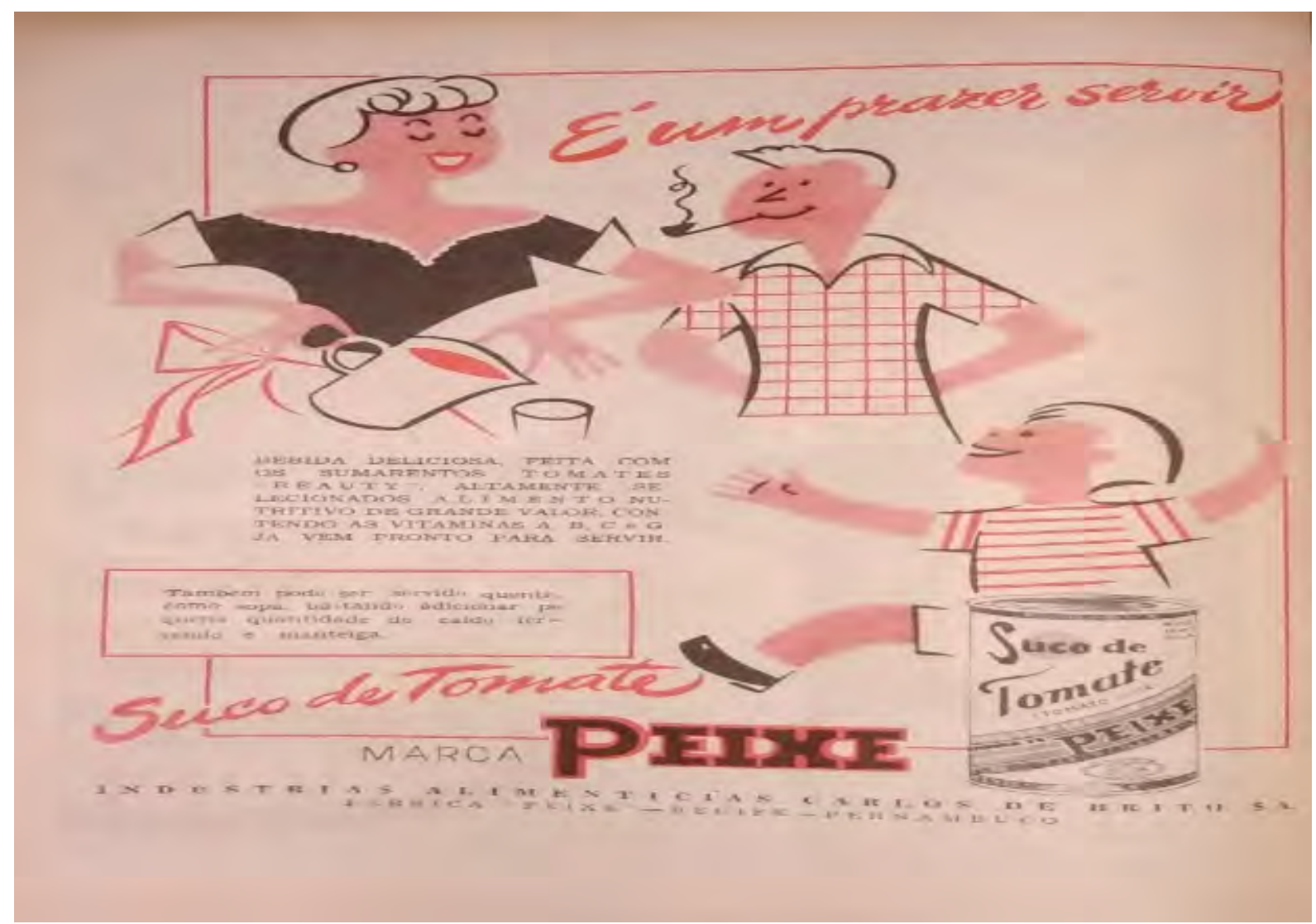

FONTE: É UM PRAZER servir (Peixe - Indústrias Alimentícias Carlos de Brito S.A.). Anuário das Senhoras, Rio de Janeiro, Sociedade anônima “O malho", ano 22, p. 138, 1955. Anual.

A representação remete à imagem de uma mulher delicada, bela e que se submete à sua família ao se dispor a servi-la, acompanhando um modelo de gênero característico da postura feminina predominante na década de 1950, possibilitado pelo "saudosismo" dos tempos pré-guerra que respingaria especialmente nos conteúdos destinados às mulheres. Isso foi perceptível tanto nas vestimentas quanto no resgate do ideal da família nuclear com os sexos bem definidos, como fala João Quintino de Medeiros Filho: 


\begin{abstract}
Pelo visto, o vestuário sexualizado foi-se modificando ao longo dos séculos, mas ainda era visto como predominante nos anos de 1950, quando o New Look trabalhou em seu proveito. [...]. Para além dessa leitura sexualista da moda, encontramos sugestões que levam à construção de uma identidade de gênero nos trajes infantis, cujas cores e adornos já apontariam modelos ideias para meninos e meninas. Esses ensinamentos estéticos seriam extremamente carregados de intenções objetivando, em última análise, o forjamento de gênero enquanto característica fatal da personalidade, da qual não se pode fugir. (MEDEIROS FILHO, 2015, p. 13)
\end{abstract}

Desse modo, entende-se também que os ideais de feminilidade deveriam ser definidos desde a infância, como percebido na publicidade dos "Docinhos Nestlé" e como se observa no anúncio da revista Almanaque de Cirandinha: "Conselho a todas as meninas, não deixem de comprar o Almanaque de Cirandinha que está um verdadeiro encanto!" (CONSELHO..., 1958, p. 1). 0 anúncio publicitário em si não sugere essa representação, contudo, sua abordagem em tom de conselho tenta incutir no leitor certo juízo de obediência, considerando, inclusive, o conteúdo da revista que possui temáticas "voltadas à culinária e aos trabalhos manuais e enfatizam a necessidade das meninas terem uma formação utilitária na qual elas deveriam estar prontas a auxiliar suas mães nos afazeres domésticos" (PATROCLO; SILVA, 2017, p. 3642).

Além dessas tarefas, outras atividades também foram exploradas nas publicidades do Anuário das Senhoras na década de 1940. 0 anúncio da cerveja Malzbier, da na época Antarctica, mostra um pouco dessa diversificação, quando a descrição do produto mostra que:

O insignificante teôr alcoolico e o esmero de sua fabricação fazem desta cerveja, de delicioso sabor e de alto valor nutritivo, uma das bebidas mais recommendaveis para todas as edades. Em quarto de garrafa, melhor se adapta á elegancia feminina. (O INSIGNIFICANTE..., 1940, p. 23)

O uso da cerveja elucida a variação de objetos em que as mulheres eram frequentemente representadas em outras publicidades. Além disso, indica a demanda de consumo feminino pelo fato de haver o desenvolvimento de um produto para um público mais específico. Contudo, devido essa bebida ser desenvolvida especialmente para elas, e ainda se mostrar utilitária para diferentes idades, sugere também um pensamento de feminilidade e posicionamento de "bom senso" perante um produto de uso comum masculino.

Esse aspecto diferenciado ainda aparece na revista do mesmo ano (figura 3), na publicidade do cigarro Continental, da Cia. Souza Cruz. No anúncio, há duas mulheres, que aparentam estar em um momento de lazer, em traje de banho, uma acendendo o cigarro da outra. 0 slogan "antes de tudo um cigarro" (ANTES..., 1940, p. 8) sugere o uso do produto antes de qualquer atividade e retrata as jovens com um ar de descanso e sensualidade. 


\section{FIGURA 3 - ANÚNCIO DO CIGARRO CONTINENTAL}

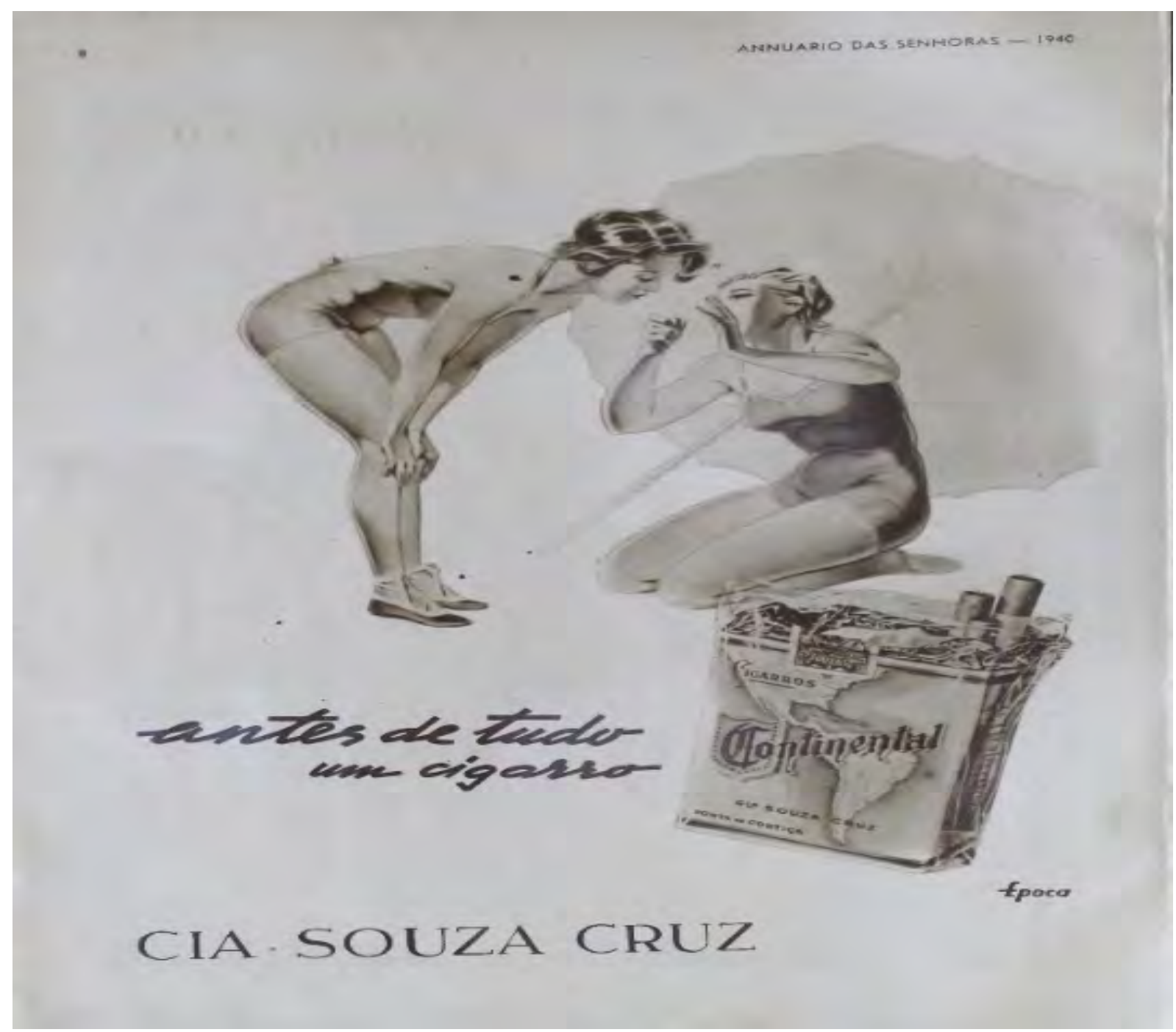

FONTE: ANTES de tudo um cigarro (Cia. Souza Cruz). Anuário das Senhoras, Rio de Janeiro, Sociedade anônima "0 malho", ano 22, p. 8, 1940. Anual.

Esse ideal de sensualidade "ingênua" (para padrões atuais) e de beleza perpassa os anúncios do Anuário das Senhoras e é bastante fomentado na publicidade da década de 1950. No anúncio do colchão de molas Lancellotti, do anuário de 1951, a frase "o seu sonho de todas as noites" (O SEU SONHO..., 1951, p. 260) aparece acompanhada da imagem de uma mulher deitada, de olhos fechados, com uma espécie de robe ou pijama (figura 4). A análise da ilustração mostra que o tom de sensualidade e de beleza é expresso pela fenda do robe que se expande desde os seios até a barriga e pela aparência ligeiramente maquiada, com cabelos em perfeito estado, mostrando, implicitamente, o dever "ser bela" até mesmo na hora de dormir, ou se deitar. 


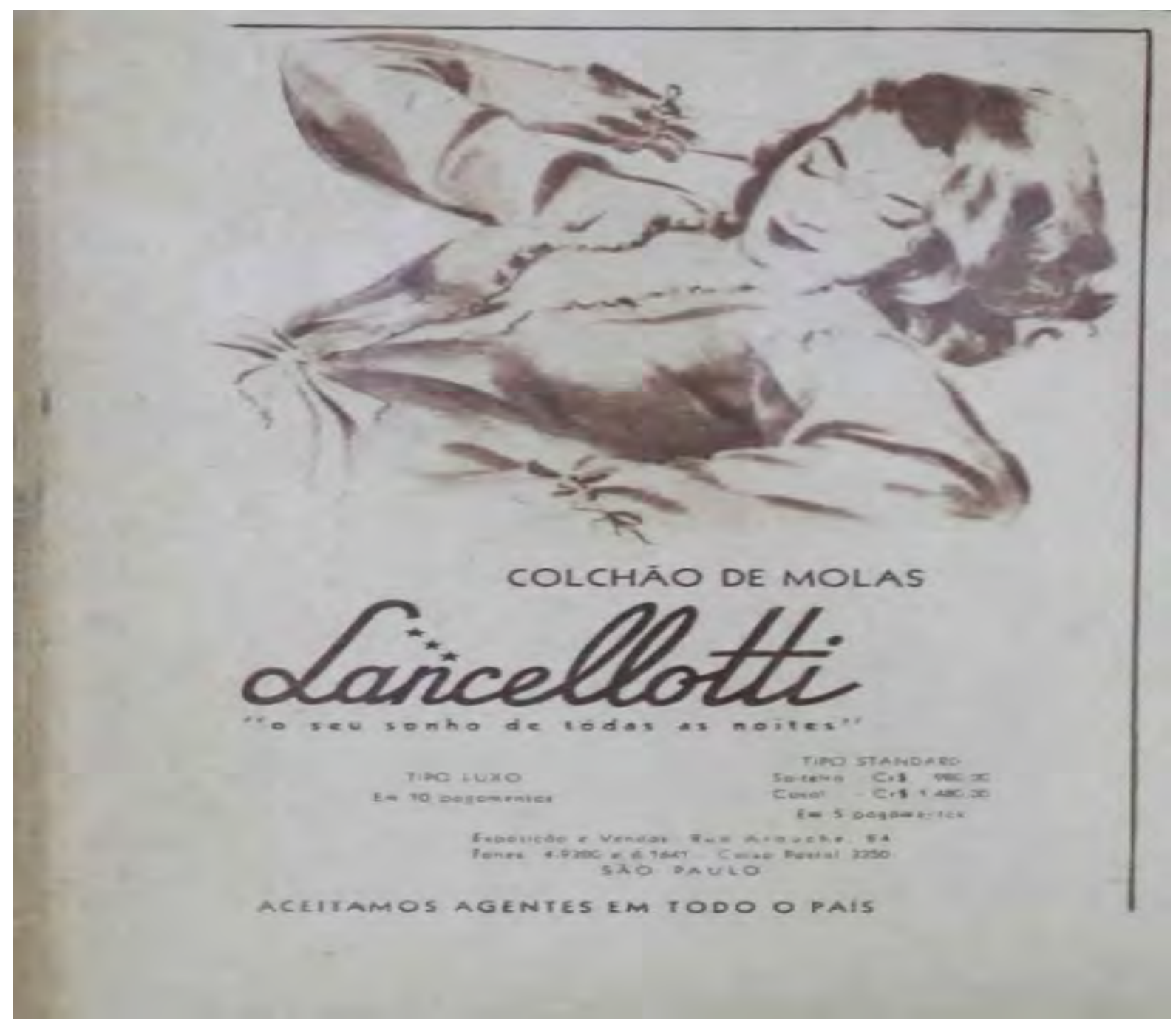

FONTE: O SEU SONHO de todas as noites (Lancellotti). Anuário das Senhoras, Rio de Janeiro, Sociedade anônima "O malho", ano 22, p. 260, 1951. Anual.

No mesmo ano, outro anúncio também apresenta a sutil imposição da mulher permanecer bela (figura 5). No entanto, o apelo à beleza mostra-se muito mais explicito quando diz:

Cabelos brancos? Sim, senhores e senhoras! É sinal de velhice! Faça-os voltar à cor natural abandone experiências e não envelheça. Reaja! Na vida a aparência é tudo. A Loção Norma normaliza o seu aspecto tornando-o belo e juvenil! Não é tintura, nem contém sais de prata. (CABELOS..., 1951, p. 282) 
Com uma voz imperativa, o texto da publicidade ordena aos homens e mulheres não cederem à velhice, colando-a a um sinal de aversão à boa aparência, ou seja, à beleza. Assim, o discurso é reforçado quando se foca na ilustração de ambos personagens, que mostra na figura feminina a jovialidade em seu rosto e em seus brilhantes cabelos negros.

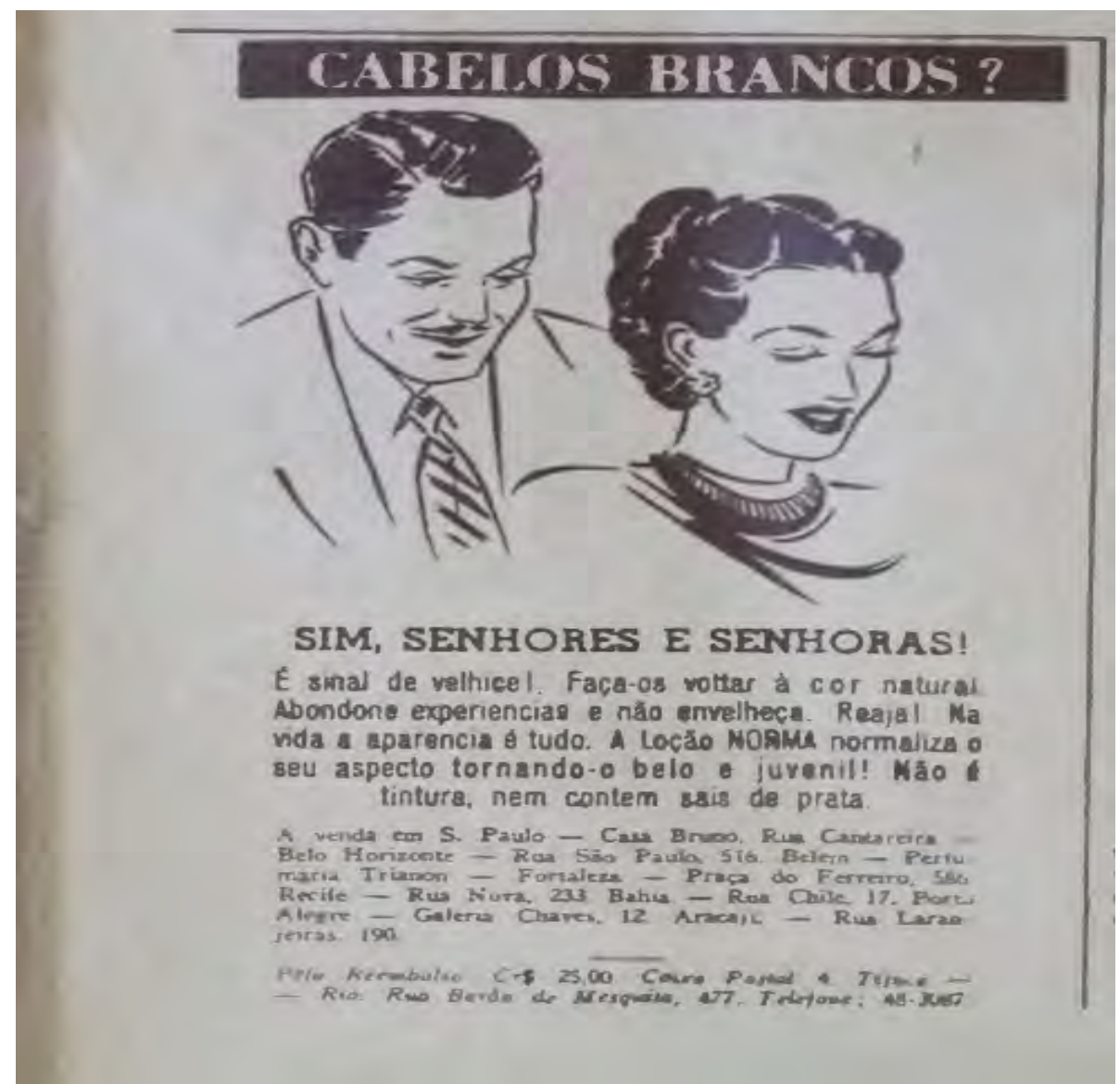

FONTE: CABELOS brancos? (Loção Norma). Anuário das Senhoras, Rio de Janeiro, Sociedade anônima "0 malho", ano 22, p. 282, 1951. Anual.

Ao reforçar a ideia de a loção não ser uma tintura, a publicidade trabalha uma noção de beleza naturalizada que, de acordo com Denise Bernuzzi de Sant’Anna, é algo característico de uma nova forma de driblar o caminho natural da idade:

0 trabalho da beleza tentaria aproximar, de modo inédito, aquilo que um rosto é de tudo o que ele aparenta ser. Como se não fosse mais honesto exibir um rosto que não se tem, como se toda distância entre a beleza natural se transformasse numa falsidade doravante intolerável. É o que ensinavam os novos conselhos de beleza, não apenas médicos e escritores do sexo masculino. (SANT'ANNA, 2014, p. 118-119) 
Desse modo, entre cigarros, loções, sucos, docinhos e cerveja, os ideais de beleza e comportamento tornam-se algo fundamental na sociedade de consumo, sendo fomentados, no anuário, principalmente para as mulheres, que estariam fadadas a perseguir, por intermédio de cosméticos ou de exercícios, a beleza em sua forma mais "natural", a juventude.

\section{Considerações finais}

As representações do feminino seguiram um ideal da moda de determinado período, isto é, as formas de pensar e perceber da própria sociedade. Por causa do contexto da Segunda Guerra Mundial, na década de 1940, a dualidade da figura feminina passou a ser vista tanto sob a forma da trabalhadora quanto da mãe e doméstica. Já nos anos 1950, acompanhou-se um ideal de mulher sob o modelo de "donzela", voltada para o lar, advindo do retorno masculino ao posto público após o término da guerra. Entretanto, isso não quer dizer que houve uma quebra de arquétipos ou que a "mulher do lar" deixou de existir na década de 1940, mas indica uma conjuntura de adaptação da sociedade e, consequentemente, de suas produções, já que, em um veículo como o Anuário das Senhoras, moda, novidade, modernidade são conduzidas para que o novo se adeque às tradições e o consumo seja um ato de comodidade e não de transformação, passando-se, assim, da moda (dinâmica) para as tintas (estática), em um movimento de adaptação e acomodação que a própria forma de anuário ajuda a estabelecer.

No que tange a publicidade como produção social, referente ao corpo e à posição da mulher, foi possível compreender seu papel como construção das representações do feminino e de reforço dos ideais de feminilidade, evidenciados pela sensualidade, pelo uso de produtos que ora se aproximam de uma noção mais feminil, ora apresentam contrastes, e pelas definições de beleza e suavidade, presentes nos sentidos que elas dão a ler. Pode-se averiguar que as publicidades no Anuário das Senhoras se enquadravam na função promotora de desejos por meio do consumo. Entretanto, além de fomentar o uso dos produtos, elas também puderam ser capazes de provocar, ou mesmo reforçar, o desejo pelas imagens representadas no que condiz a aquisição estética ou de um estilo de vida.

Assim, as publicidades, por meio das representações de seus anúncios, fizeram uma leitura social que puderam mostrar em imagens e textos, dentro de suas ressalvas, um contorno daquilo que circundava o comportamento feminino e os contextos de cada período. Portanto, mesmo que cada anúncio seja uma interpretação entre as muitas existentes, ele demonstra possibilidades de modos de ver que puderam ser acompanhados e relidos pelo público leitor feminino do anuário.

Por meio da publicidade, as representações foram formuladas e transmitidas ao idealizar uma imagem simbólica feminina. Ademais, vale salientar que o Anuário das Senhoras, apesar de periódico, também era um livro, uma vez que possuía uma função mais duradoura, uma ideia de presença constante, de pertencimento e consulta que as revistas e os jornais não tinham. Assim, tanto o texto quanto as publicidades nele presentes poderiam ser mais revisitados, ampliando a ideia de construção do real pela representação sempre revivida como reforço dos conceitos veiculados. 


\section{Referências}

BERGER, John. Modos de ver. 3. ed. Espanha: Gustavo Gili, 2004.

CALANCA, Daniela. A história social da moda. 2. ed. São Paulo: Editora Senac São Paulo, 2011.

CONSELHO a todas as meninas (Almanaque de Cirandinha). Anuário das Senhoras, Rio de Janeiro, Sociedade anônima "O malho", ano 22, p. 1, 1958. Anual.

CHARTIER, Roger. A história cultural: entre práticas e representações. Lisboa: Difel, 1988.

CHARTIER, Roger. 0 mundo como representação. Estudos avançados. São Paulo, v. 5, n.11, 1991. Disponível em: http://www.revistas.usp.br/eav/article/view/8601. Acesso em: 14 jul. 2018.

GARCIA, Janaína A. Beraldo. Escola de modelos: três décadas do Anuário das Senhoras (1934-1954). 2004, 176 f. Dissertação (Mestrado) - Curso de Pós-Graduação em História, Universidade Federal do Paraná, Curitiba, 2004.

HABERMAS, Jürgen. Mudança estrutural da esfera pública: investigações quanto a uma categoria da sociedade burguesa. Rio de Janeiro: Tempo Brasileiro, 2003.

LIPOVETSKY, Gilles. 0 império do efêmero: a moda e seu destino nas sociedades modernas. São Paulo: Companhia das Letras, 2009.

LUCA, Tania Regina de. Fontes impressas: a história dos, nos e por meio dos periódicos. In: PINSKY, Carla Bassanezi (org.). Fontes históricas. São Paulo: Contexto, 2005.

LUCA, Tania Regina de. Imprensa feminina: mulher em revista. In: PINSKY, Carla Bassanezi; PEDRO, Joana Maria (orgs.). Nova história das mulheres do Brasil. São Paulo: Contexto, 2013.

MEDEIROS FILHO, João Quintino de. Moda e gênero: o vestuário sexualizado no New Look de Christian Dior. Mneme: Revista de Humanidades (Dossiê História do Corpo), Caicó, v. 16, n. 37, p. 10-36, jul./dez. 2015. Disponível em: https://periodicos.ufrn.br/mneme/ article/viewFile/8174/6194. Acesso em: 14 jul. 2018.

MIRA, Maria Celeste. 0 leitor e a banca de revistas: a segmentação da cultura no século XX. São Paulo: Olho D’água, 2003.

O INSIGNIFICANTE... (Antarctica). Anuário das Senhoras, Rio de Janeiro, Sociedade anônima “0 malho”, ano 22, p. 23, 1940. Anual. 
PATROCLO, Luciana Borges; SILVA, Sabrinne Cordeiro Barbosa da. As revistas ilustradas infantis como fontes de pesquisa na história da educação: o exemplo do impresso feminino Cirandinha (1951-1958). In: IX CONGRESSO BRASILEIRO DE HISTÓRIA DA EDUCAÇÃO História da Educação: global, nacional e regional. [Anais...]. Paraíba: João Pessoa, UFPB, 2017. p. 1-867.

PREFÁCIO. Anuário das Senhoras, Rio de Janeiro: Sociedade anônima “O malho", ano 22, p. 1, 1940. Anual.

SANT’ANNA, Denise Bernuzzi de. Corpo e beleza: "sempre bela". In: PINSKY, Carla Bassanezi; PEDRO, Joana Maria (orgs.). Nova história das mulheres do Brasil São Paulo: Contexto, 2013.

SANT'ANNA, Denise Bernuzzi de. A história da beleza no Brasil. São Paulo: Contexto, 2014.

SVENDSEN, Lars. Moda: uma filosofia. Rio de Janeiro: Zahar, 2010.

WILLIAMS, Raymond. Publicidade: o sistema mágico. In: WILLIAMS, Raymond. Cultura e materialismo. Trad. André Glaser. São Paulo: Editora Unesp, 2011. 